NASA/TM-2002-211698

ICOMP-2002-03
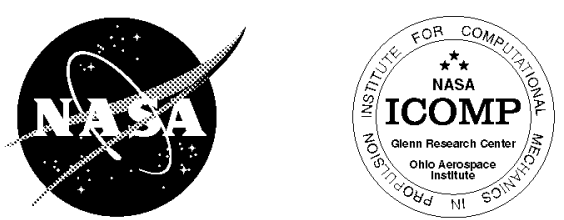

AIAA-2002-3629

\title{
Thermodynamic Cycle and CFD Analyses for Hydrogen Fueled Air-Breathing Pulse Detonation Engines
}

Louis A. Povinelli

Glenn Research Center, Cleveland, Ohio

Shaye Yungster

Institute for Computational Mechanics in Propulsion, Cleveland, Ohio 
The NASA STI Program Office ... in Profile

Since its founding, NASA has been dedicated to the advancement of aeronautics and space science. The NASA Scientific and Technical Information (STI) Program Office plays a key part in helping NASA maintain this important role.

The NASA STI Program Office is operated by Langley Research Center, the Lead Center for NASA's scientific and technical information. The NASA STI Program Office provides access to the NASA STI Database, the largest collection of aeronautical and space science STI in the world. The Program Office is also NASA's institutional mechanism for disseminating the results of its research and development activities. These results are published by NASA in the NASA STI Report Series, which includes the following report types:

- TECHNICAL PUBLICATION. Reports of completed research or a major significant phase of research that present the results of NASA programs and include extensive data or theoretical analysis. Includes compilations of significant scientific and technical data and information deemed to be of continuing reference value. NASA's counterpart of peerreviewed formal professional papers but has less stringent limitations on manuscript length and extent of graphic presentations.

- TECHNICAL MEMORANDUM. Scientific and technical findings that are preliminary or of specialized interest, e.g., quick release reports, working papers, and bibliographies that contain minimal annotation. Does not contain extensive analysis.

- CONTRACTOR REPORT. Scientific and technical findings by NASA-sponsored contractors and grantees.
- CONFERENCE PUBLICATION. Collected papers from scientific and technical conferences, symposia, seminars, or other meetings sponsored or cosponsored by NASA.

- SPECIAL PUBLICATION. Scientific, technical, or historical information from NASA programs, projects, and missions, often concerned with subjects having substantial public interest.

- TECHNICAL TRANSLATION. Englishlanguage translations of foreign scientific and technical material pertinent to NASA's mission.

Specialized services that complement the STI Program Office's diverse offerings include creating custom thesauri, building customized data bases, organizing and publishing research results ... even providing videos.

For more information about the NASA STI Program Office, see the following:

- Access the NASA STI Program Home Page at http://www.sti.nasa.gov

- E-mail your question via the Internet to help@sti.nasa.gov

- Fax your question to the NASA Access Help Desk at 301-621-0134

- Telephone the NASA Access Help Desk at 301-621-0390

- Write to: NASA Access Help Desk NASA Center for AeroSpace Information 7121 Standard Drive Hanover, MD 21076 

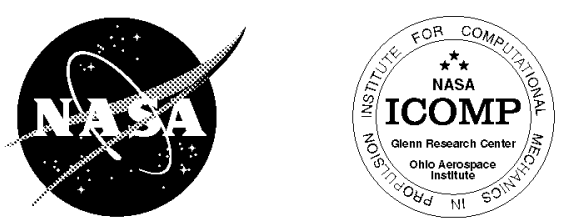

\section{Thermodynamic Cycle and CFD Analyses for Hydrogen Fueled Air-Breathing Pulse Detonation Engines}

Louis A. Povinelli

Glenn Research Center, Cleveland, Ohio

Shaye Yungster

Institute for Computational Mechanics in Propulsion, Cleveland, Ohio

Prepared for the

38th Joint Propulsion Conference and Exhibit cosponsored by the AIAA, ASME, SAE, and ASEE

Indianapolis, Indiana, July 7-10, 2002

National Aeronautics and

Space Administration

Glenn Research Center 
Available from

NASA Center for Aerospace Information 7121 Standard Drive

Hanover, MD 21076
National Technical Information Service 5285 Port Royal Road Springfield, VA 22100

Available electronically at http://gltrs.grc.nasa.gov/GLTRS 


\title{
THERMODYNAMIC CYCLE AND CFD ANALYSES FOR HYDROGEN FUELED AIR-BREATHING PULSE DETONATION ENGINES
}

\author{
Louis A. Povinelli ${ }^{*}$ \\ National Aeronautics and Space Administration \\ Glenn Research Center \\ Cleveland, Ohio 44135 \\ Shaye Yungster ${ }^{\dagger}$ \\ Institute for Computational Mechanics in Propulsion \\ National Aeronautics and Space Administration \\ Glenn Research Center \\ Cleveland, Ohio 44135
}

\begin{abstract}
This paper presents the results of a thermodynamic cycle analysis of a pulse detonation engine (PDE) using a hydrogen-air mixture at static conditions. The cycle performance results, namely the specific thrust, fuel consumption and impulse are compared to a single cycle CFD analysis for a detonation tube which considers finite rate chemistry. The differences in the impulse values were indicative of the additional performance potential attainable in a PDE.
\end{abstract}

\section{Introduction}

Previous studies have demonstrated the impact of dissociation in propulsion engines. ${ }^{1}$ A significant reduction in the sensible heat release available for conversion into thrust occurs due the to high temperature dissociation of the burning gases. A subsequent analysis ${ }^{2}$ was performed in which the specific thrust, fuel consumption and impulse were compared for a ramjet, a gas turbine and a PDE. In that study, it was found that a PDE has comparable performance with a ramjet over a wide Mach number range. In comparison with a turbojet the PDE was found to be competitive only when the turbojet was operated with a low mechanical compression ratio. More recently, a single cycle CFD analysis was performed for a detonation tube, ${ }^{3}$ which included finite rate chemistry modeling.

It was found that some recombination took place in the burning gases behind the detonation front. ${ }^{3}$ The recombination served to decrease the amount of

\footnotetext{
* Chief Scientist, Turbomachinery and Propulsion Systems Division

Senior Research Associate, Ohio Aerospace Institute
}

sensible heat loss that occurred during the detonation process due to dissociation

This paper examines the effect of the real gas chemistry, using a combination of the single cycle CFD and the thermodynamic cycle calculations for hydrogen/air mixtures. The results are used to establish the actual performance of a PDE versus the maximum performance potential.

\section{Analyses}

\section{Thermodynamic Cycle}

The thermo cycle analysis used was that developed by Heiser and Pratt $^{4}$ and modified in reference 2 for variable gamma and specific heat ratio and for variable reference conditions. The analysis is a classical closed cycle analysis that is independent of time. The significant parameters of the analysis are the thermal efficiency and the sensible heat release, which can be converted into thrust. Those values can be used to calculate all of the usual performance parameters, such as specific thrust, fuel consumption and impulse. In this manner, the maximum performance capability for a pulse detonation engine can be established.

In order to perform the cycle analysis, it is necessary to specify the heat release occurring during the detonation/combustion process. The usual practice has been to assume that the lower heating value of the fuel is a reasonable value to use. As mentioned in the Introduction, the real gas effects such as dissociation and recombination cause the sensible heat release to be 
less than the lower heating value of the fuel. ${ }^{1}$ The decrease in heat release turns out to be a function of equivalence ratio, pressure and temperature as well as fuel type.

In this study, the sensible heat release during the detonation/combustion process was determined in two ways; the first being the value calculated from the CEA equilibrium $\operatorname{code}^{5}$ and the second being the heat released based on finite rate reactions from the CFD code discussed in the next section. Unlike the equilibrium value, the finite rate heat release accounts for recombination and yields a higher heat release value.

The two values of the heat release were used in the cycle code to determine the specific thrust, fuel consumption and impulse for a hydrogen/air mixture at standard pressure and temperature. The equivalence ratios investigated were $0.6,0.8,1.0$, and 1.15 . The results consisted of two values of each of the performance parameters, one based on the equilibrium heat release and the other on the finite rate heat release.

The propulsion performance parameters were then interpreted under the premise that the equilibrium heat release did not reflect the influence of recombination on heat release and hence, yields a lower than maximum performance for the PDE. On the other hand, the finite rate heat release, which properly accounts for both dissociation and recombination, will yield the upper limit of performance potential for a PDE cycle.

\section{CFD Analysis}

The CFD analysis used was developed by Yungster and Radhakrishnan. ${ }^{6-8}$ The code solves the axisymmetric Navier Stokes equations including finite rate chemistry and real gas effects using an implicit, total-variation diminishing (TVD) algorithm. The code includes a generalized detailed chemistry capability, various options for turbulence models, and steady state or time accurate marching algorithms. For this study, the viscous forces were not included and, therefore the Euler equations were actually used to perform single cycle calculations.

The numerical method used for solving the governing equations is described in detail in reference 6 . Briefly, the equation set is discretized using a fully implicit, first order time accurate, variable-step backward differentiation formula method. The numerical fluxes are discretized using a second order spatially accurate TVD scheme. The resulting equations are then linearized in a conservative manner and solved iteratively, by using a lower-upper relaxation procedure consisting of successive Gauss-Seidel (LU-SGS) sweeps.

The chemical reaction mechanism for hydrogen-air combustion was based on Jachimowski's model ${ }^{9}$ and consists of 27 elementary reactions among 12 species. The inversion of large matrices is avoided by partitioning the system into reacting and non-reacting parts. Consequently, the matrices that have to be inverted are of the same size as those that arise in the commonly used point implicit methods. An important advantage of the present method is that it is stable for large CLF values, thereby enabling the use of large time steps to minimize computational cost.

In order to maintain good resolution of the detonation front at all times a multi-level, dynamically adaptive grid was used in which a very fine sub-grid continuously slides along with the detonation wave front. ${ }^{8}$ This approach avoided the use of thousands of grid points.

The CFD finite rate calculations were used to compute the species evolution and the resulting thrust and impulse. They were also used to determine the sensible heat release occurring during the detonation and combustion processes for the hydrogen-air mixtures at the same equivalence ratios used in the thermo cycle analyses.

\section{Comparative Analysis}

The comparison of the cycle code and the CFD calculations was carried out as shown in figure 1 . The cycle analysis used the sensible heat release determined from EQL to calculate the performance parameters and then used the finite rate value from the CFD to yield a second set of values. It is the second set, which is based on the finite rate heat release, that are believed to yield the maximum performance (upper cycle) limits for a PDE.

In the CFD analysis, detonation is initiated in a one meter length tube with a diameter of 6.6 centimeters using a $2 \mathrm{~cm}$ zone of high temperature nitrogen at $2500 \mathrm{~K}$ and 40 bar. The tube is filled with hydrogen/air at $298 \mathrm{~K}$ and 1 bar. This starting transient is neglected in the "ignition corrected" values of performance, whereas, in the "uncorrected results," the transient was included. This correction is justified on the basis of the need to introduce an ignition mechanism to obtain detonation, which creates an artificial force that is not representative of the actual ignition process ${ }^{3}$. The resulting values of the corrected parameters are believed to be representative of the flow geometry being analyzed. Figure 2 (from ref. 3 ) shows the result 
of the ignition correction. Further efforts are underway to reduce the size of the ignition source and the corresponding correction required.

\section{System Analyzed}

For the thermodynamic cycle, it is assumed that the inlet has no losses and operates in an isentropic manner. The pressure and temperature are at standard conditions for this example. There is no ram pressure since the forward velocity is zero, i.e. static thrust conditions. The nozzle, which may be of any shape, is also assumed to be isentropic, yielding the maximum thrust for the operating conditions of the detonation chamber. Although a nozzle geometry having this characteristic is unknown at this time, it is not required for a cycle calculation, which seeks the upper performance capability of a PDE.

For the CFD analysis, the inlet again is assumed to have no losses. Admission of fuel and air occurs with no entropy generation. In fact, for the analysis, it is assumed that the detonation chamber is closed at the front end for the single cycle being analyzed.

However, in order to perform the CFD analysis a description of the geometry at the downstream end is required. In the absence of any specific design, it is assumed that the detonation chamber is open at the downstream end and has a constant diameter throughout and discharges to an ambient pressure of 1 bar. In this case, the CFD analysis, with the proper boundary conditions, should yield the "actual" performance for that geometry subject to the approximations in the solved equations, including the neglect of viscous effects. The term "actual" in this case refers to the fact that the expansion process is not isentropic. Hence, the difference between the thermo cycle analysis and the CFD will be due to the nonisentropic nozzle expansion losses and some frictional effects.

The analyzed geometry, therefore, is as shown in figure 3 .

\section{$\underline{\text { Results }}$}

\section{Sensible Heat Release}

The heat releases calculated using the equilibrium code of Gordon and McBride, ${ }^{5}$ and the finite rate CFD chemistry model are shown in figure 4 . The differences in the two curves are due to the recombination that occurs as the heated gases burn and flow out of the detonation tube. As the gases recombine, additional heat is released.
The loss in sensible heat is found to be much larger at the higher equivalence ratios and is primarily due to the higher detonation temperatures reached. For an equivalence ratio of 0.6 , the detonation temperature is $2422 \mathrm{~K}$ and for a value of 1.15 , the temperature reaches $2967 \mathrm{~K}$.

\section{Thermo Cycle and CFD Analyses}

Using the above variation of heat release values, the thermo cycle code yields the fuel specific impulse results shown in figure 5. As noted previously, the higher sensible heat associated with finite rate chemistry lead to higher values of impulse than those associated with equilibrium chemistry.

It is the performance associated with the finite rate results that are interpreted as the upper limit of PDE propulsion performance.

The ignition corrected results from the CFD analysis are shown in figure 6. As stated previously, the artificial force created by the ignition effect is not considered representative of the actual ignition process, and the resulting values of the ignition corrected values are believed to be accurate for the flow geometry being analyzed.

As stated in the Analyses section under Thermodynamic Cycle, the interpretation of the results is that the equilibrium heat release does not reflect the influence of recombination on heat release and hence, yields a lower than maximum performance for the PDE. On the other hand, use of the finite heat release in the thermo cycle, which correctly accounts for both dissociation and recombination, yields the upper cycle limit for the propulsion performance of a PDE cycle.

Plotting the thermo cycle finite rate result from figure 5 and the CFD ignition corrected finite rate results from figure 6 yields the plot shown in figure 7 .

The differences in the two curves of figure 7 represent the losses principally incurred by the open-ended detonation tube and the nature of the non-isentropic expansion. The losses are on the order of 5 percent ( 250 seconds) of the impulse.

It is interesting to observe that the ratio of the impulse values from the CFD to the impulse value of the thermo cycle calculations, $\left(\mathrm{I}_{\mathrm{CFD}} / \mathrm{I}\right.$ thermo), have values from 0.94 to 0.95 . It is informative, therefore, to look at the values determined by the cycle analysis using a nozzle efficiency of 0.95 . When these calculations are performed, the impulse values turn out to be 6 percent lower, which is close to our expectations. 
The differences in the two curves of figure 7, which are taken to be the real performance versus the potential performance, are seen to amount to values between 200 and 300 seconds. These differences, once again, emphasize the critical nature of the nozzle exhaust design in order to achieve the potential gain in PDE propulsion performance. ${ }^{4}$

\section{Comparison with Experimental Data}

The data obtained in this study were compared to that obtained at the Wright Labs by Schafer, Stutrud and Bradley. ${ }^{10}$ In figure 8 , our data points (from figure 7 described above) are shown on a copy of the impulse versus equivalence plot from figure 12 of reference 10 . The open squares represent our thermo cycle upper performance limit and the open diamond symbols represent our ignition corrected finite rate CFD results. The CFD results are in excellent agreement with the data and the cycle results show the potential improvement. Note that the differences were more clearly depicted in figure 7. Also shown in the figure are the results for a single cycle PDE engine (openended tube) based on a model using gas dynamic calculations and experimental results. ${ }^{11}$

\section{Specific Thrust and Fuel Consumption}

The specific thrust and fuel consumption were also determined using the cycle analysis and are shown in figures 9 and 10. In these calculations, only the finite rate heat release values were used. These results represent the maximum or upper limit values for the thrust and fuel consumption, as was the case for the impulse values.

\section{Conclusions}

A combination of a thermodynamic cycle and a CFD finite rate code were used to analyze detonation behavior in order to establish an upper limit for PDE cycle performance.

The thermo cycle code was used with both equilibrium and finite rate sensible heat release values. It was determined that the recombination occurring during the detonation/combustion process required the use of the finite rate values to accurately capture the real gas effects.

The CFD finite rate heat release was found to be high due to the ignition mechanism, which caused a large force that is not representative of the actual ignition process. These values were corrected and used for determining propulsion parameters, which in turn, were compared with the thermo cycle finite rate results. The comparisons established the cycle upper limits for PDE performance and the potential gains that may be realized in PDE nozzle design.
Comparison with available data showed agreement with both the cycle analysis, namely the maximum upper limit values, and between the CFD and experimental data, namely the actual performance.

\section{References}

1. Povinelli, Louis A., "Impact of Dissociation and Sensible Heat release on Pulse Detonation and Gas Turbine Engine Performance," NASA/TM-2001, July 2001, also 15th ISABE Symposium Paper 2001-1212, Sept. 2002.

2. Povinelli, L., Lee, J.-H. and Landenberg, M., "Role of Air-Breathing Pulse Detonation Engines in High Speed Propulsion," NASA/TM-2001-211163, Sept. 2001, also 52nd International Astronautically Congress Paper IAF-01-S.5.01, Oct. 2001.

3. Povinelli, Louis A., and Yungster, Shaye, "Airbreathing Pulse Detonation Engine Performance," NASA/TM-2002-211575, also JANNAF Conference, 26th Airbreathing Propulsion Subcommittee, Destin, FL, April 8-12, 2002.

4. Heiser, William. H., and Pratt, David T., "Thermodynamic Cycle Analysis of Pulse Detonation Engines," Jrl. of Propulsion and Power, Vol. 18, No. 1, January-February 2002.

5. Gordon. S., and McBride. B, "Computer Program for Calculation of Complex Chemical Equilibrium Compositions and Applications, Part 1. Analysis," NASA RP-1311, June 1966.

6. Yungster, S. and Radhakrishnan, K., "A Fully Implicit Time Accurate Method for Hypersonic Combustion: Application to Shock Induced Combustion Instability," Shock Waves, Vol. 5, 1996, pp. 293-303.

7. Yungster, S. and Radhakrishnan, K., "Simulation of Unsteady Hypersonic Combustion Around Projectiles in an Expansion Tube," Shock Waves, Vol. 11, 2001, pp. 167-177.

8. Yungster, S, and Radhakrishnan, K., "Computational Study of Near-Limit Propagation of Detonation in Hydrogen-Air Mixtures," 38th AIAA/ASME/SAE/ASEE Joint Propulsion Conference, Indianapolis, Indiana, July 7-10, 2002.

9. Jackomowski, C.J., "An Analytical Study of the Hydrogen-Air Reaction Mechanism with Application to Scramjet Combustion," NASA TP-2791, Feb. 1988.

10. Schauer, Fred, Stutrud, Jeff, and Bradley, Royce, "Detonation Initiation Studies and Performance Results for Pulse Detonation Engine Applications," AIAA Paper 2001-1129.

11. Wintenberger, E., Austin, J.M., Cooper, S., and Shepherd, J.E., "An Analytical Model for the Impulse of a Single-Cycle Pulse Detonation Engine," AIAA Paper 01-34455, July 2001. 
Thermodynamic cycle analysis

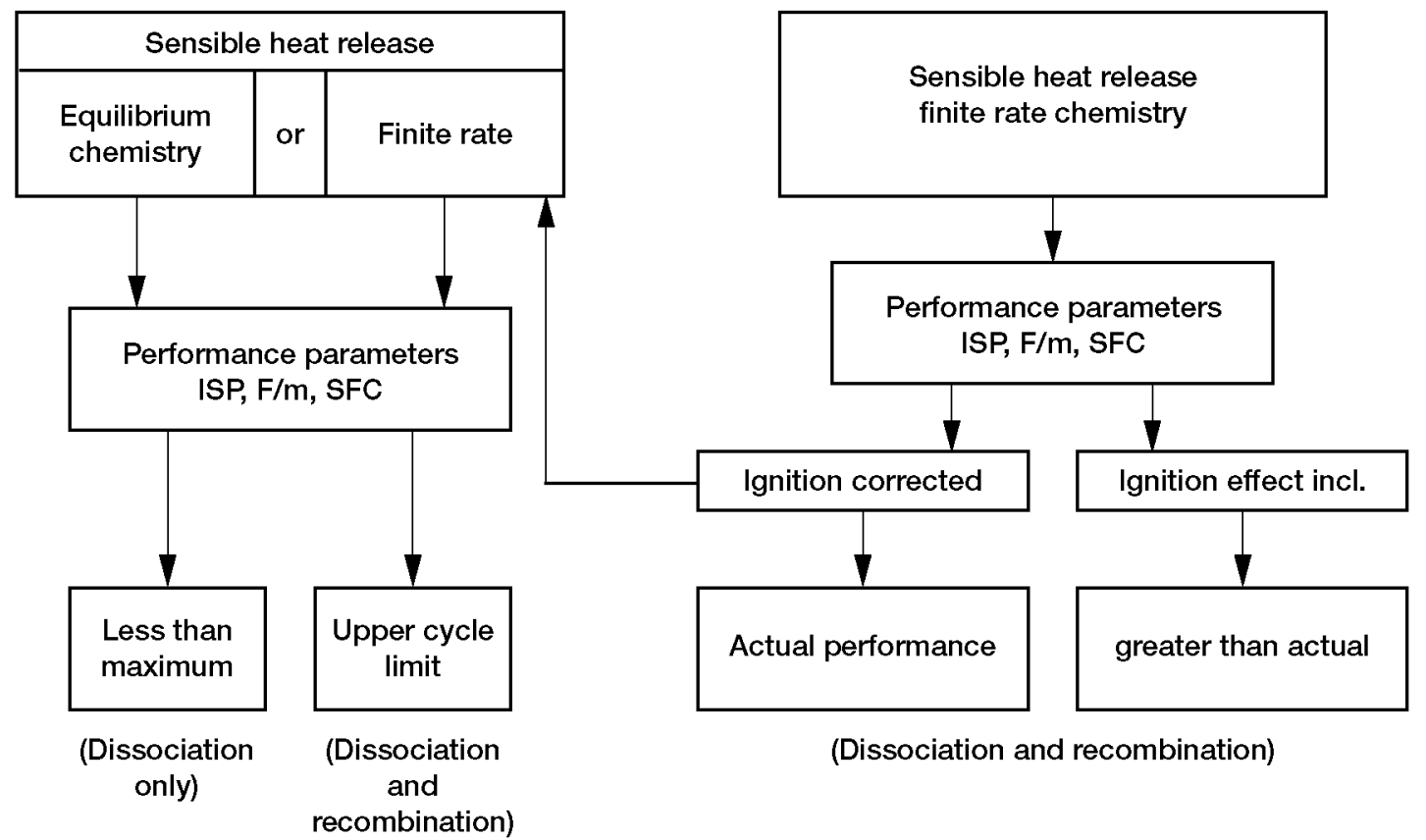

Figure 1.-Block diagram illustrating the comparative analyses. 

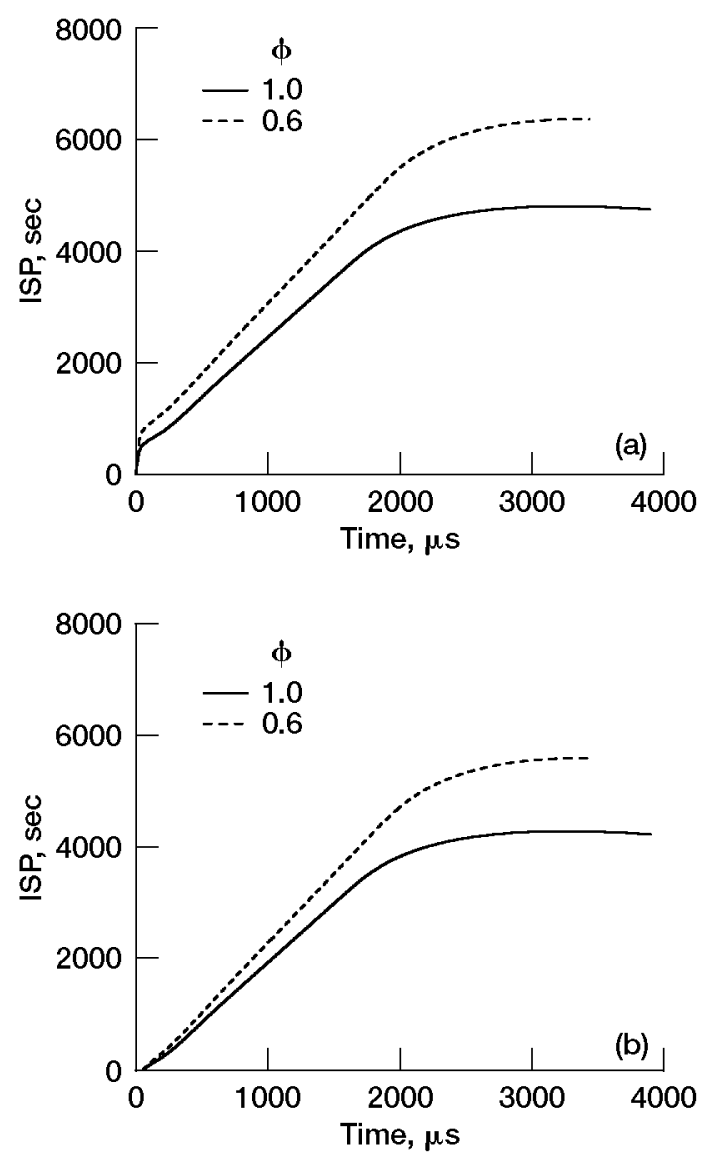

Figure 2.-Comparison of specific impulse between the finite rate chemistry computations for $\phi=1.0$ and $\phi=0.6$. In part (b), the force produced during the starting transient phase (first $50 \mu \mathrm{sec}$ ) was neglected.

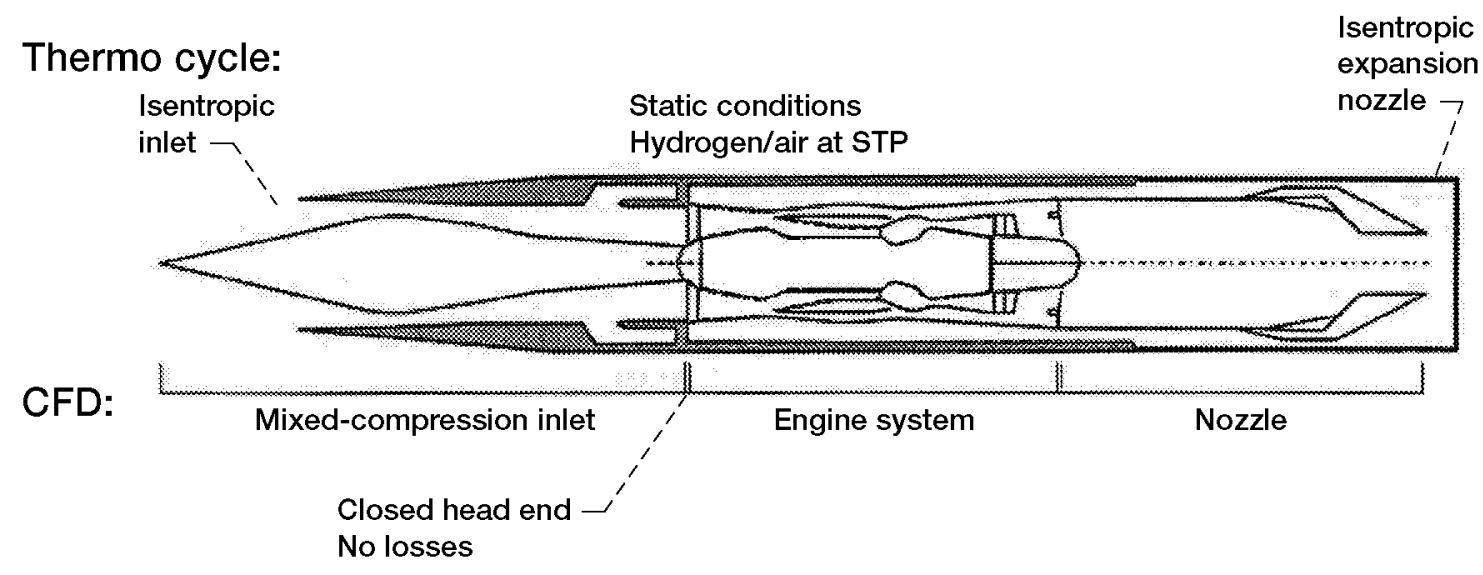

Figure 3.-Comparison of model geometries for notional engine. 


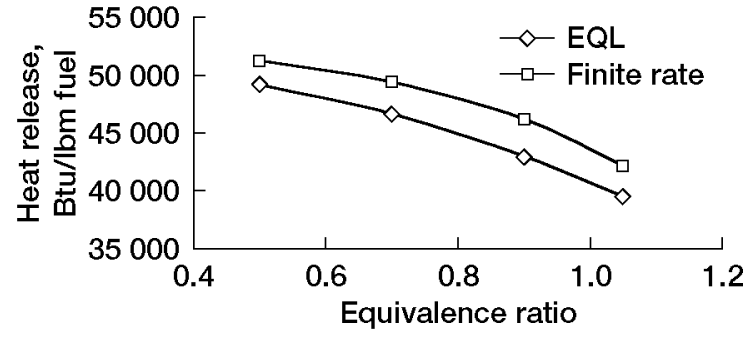

Figure 4.- Heat release determined from EQL and CFD analysis.

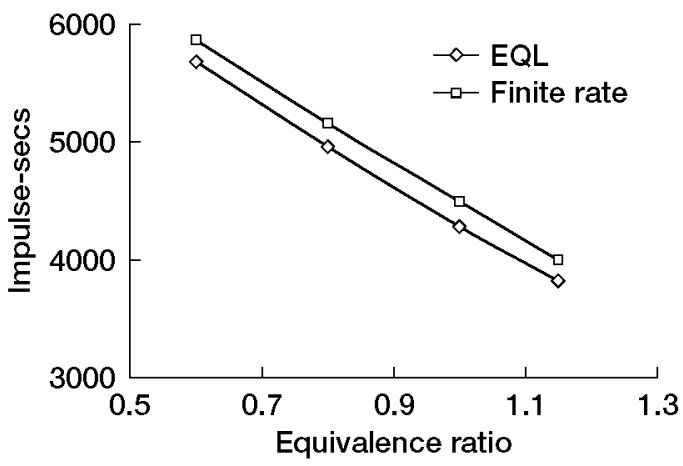

Figure 5.-Impulse calculated from cycle analysis.

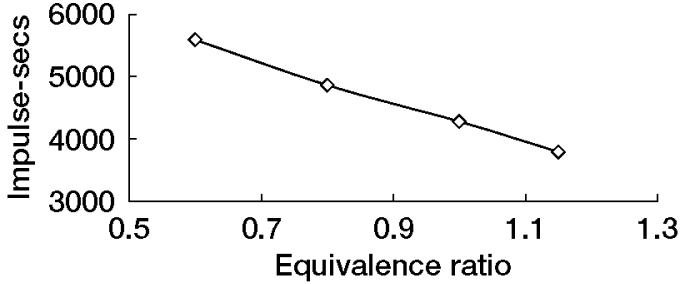

Figure 6.-Impulse calculated from CFD analysis.

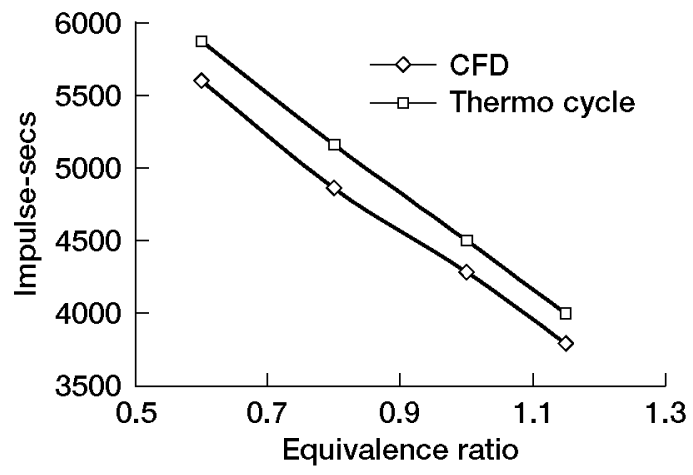

Figure 7.-Potential improvement in impulseactual and upper limit values. 


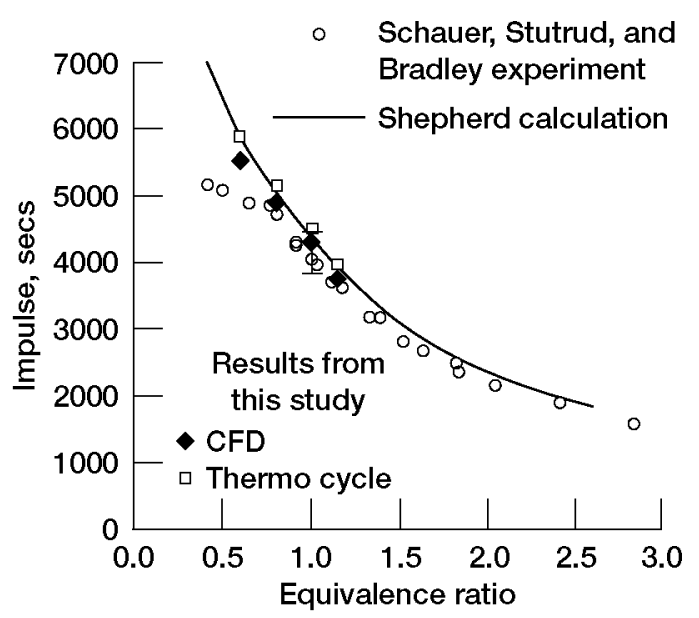

Figure 8.-Calculated cycle and CFD impulse superposed on figure 12 of reference 10.

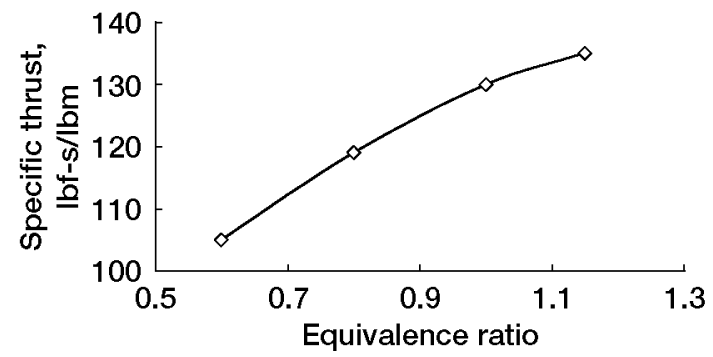

Figure 9.-Specific thrust from cycle analysis with finite rate heat release.

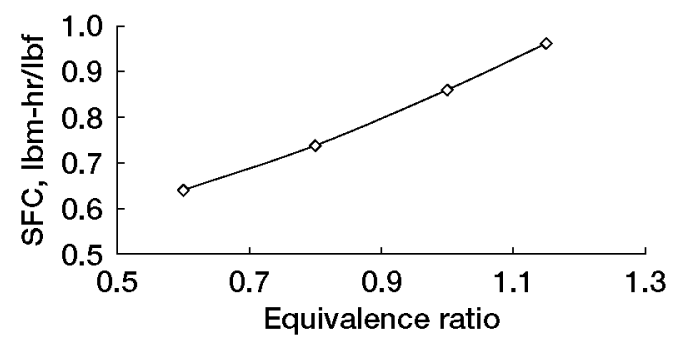

Figure 10.-Specific fuel consumption-cycle analysis with finite rate heat release. 


\section{REPORT DOCUMENTATION PAGE}

Public reporting burden for this collection of information is estimated to average 1 hour per response, including the time for reviewing instructions, searching existing data sources, gathering and maintaining the data needed, and completing and reviewing the collection of information. Send comments regarding this burden estimate or any other aspect of this collection of information, including suggestions for reducing this burden, to Washington Headquarters Services, Directorate for Information Operations and Reports, 1215 Jefferson Davis Highway, Suite 1204, Arlington, VA 22202-4302, and to the Office of Management and Budget, Paperwork Reduction Project (0704-0188), Washington, DC 20503.

\section{\begin{tabular}{l|l|l} 
1. AGENCY USE ONLY (Leave blank) & 2. REPORT DATE & 3. REPORT TYPE AND DATES COVERED
\end{tabular}}

\section{TITLE AND SUBTITLE}

June 2002

Technical Memorandum

Thermodynamic Cycle and CFD Analyses for Hydrogen Fueled Air-Breathing

Pulse Detonation Engines

6. AUTHOR(S)

Louis A. Povinelli and Shaye Yungster

\section{PERFORMING ORGANIZATION NAME(S) AND ADDRESS(ES)}

National Aeronautics and Space Administration

John H. Glenn Research Center at Lewis Field

Cleveland, Ohio 44135-3191

\section{SPONSORING/MONITORING AGENCY NAME(S) AND ADDRESS(ES)}

National Aeronautics and Space Administration

Washington, DC 20546-0001 REPORT NUMBER

E-13431

WU-706-21-33-00

10. SPONSORING/MONITORING AGENCY REPORT NUMBER

NASA TM-2002-211698

ICOMP-2002-03

AIAA-2002-3629

\section{SUPPLEMENTARY NOTES}

Prepared for the 38th Joint Propulsion Conference and Exhibit cosponsored by the AIAA, ASME, SAE, and ASEE, Indianapolis, Indiana, July 7-10, 2002. Louis A. Povinelli, NASA Glenn Research Center; and Shaye Yungster, Institute for Computational Mechanics in Propulsion, Cleveland, Ohio. Responsible person, Louis A. Povinelli, organization code 5000, 216-433-5818.

12a. DISTRIBUTION/AVAILABILITY STATEMENT 12b. DISTRIBUTION CODE

Unclassified - Unlimited

Subject Category: 07

Distribution: Nonstandard

Available electronically at htp//gltrs grenasa.gov/GLTRS

This publication is available from the NASA Center for AeroSpace Information, 301-621-0390.

13. ABSTRACT (Maximum 200 words)

This paper presents the results of a thermodynamic cycle analysis of a pulse detonation engine (PDE) using a hydrogenair mixture at static conditions. The cycle performance results, namely the specific thrust, fuel consumption and impulse are compared to a single cycle CFD analysis for a detonation tube which considers finite rate chemistry. The differences in the impulse values were indicative of the additional performance potential attainable in a PDE.

\section{SUBJECT TERMS}

15. NUMBER OF PAGES

Pulse detonation engines; Propulsion; Advanced propulsion systems

17. SECURITY CLASSIFICATION OF REPORT

Unclassified

18. SECURITY CLASSIFICATION
OF THIS PAGE
Unclassified

19. SECURITY CLASSIFICATION OF ABSTRACT

Unclassified
14

16. PRICE CODE 